\title{
ANÁLISE HISTÓRICA DAS PRÁTICAS DE ENFERMAGEM NO CAMPO DA ASSISTÊNCIA PSIQUIÁTRICA NO BRASIL, NO PERÍODO COMPREENDIDO ENTRE AS DÉCADAS DE 20 E 50*
}

KIRSCHBAUM.,D.I.R., Análise Histórica das Práticas de Enfermagem no campo da Assistência Psiquiátrica no Brasil, no período compreendido entre décadas de 20 e 50. Rev.latino-am.enfermagem, Ribeirão Preto, v. 5, número especial, p. 19-30, maio 1997.

Este estudo enfoca a relação existente entre o projeto psiquiátrico implementado no Brasil a partir do final do século XIX e as práticas de preparação do pessoal de enfermagem desenvolvidas em instituições psiquiátricas brasileiras, entre os anos 20 e 50, utilizando a história oral como método de pesquisa. Através da reconstituição histórica de certos aspectos que caracterizaram a organização da assistência psiquiátrica no país e as formas assumidas pelos processos de formação do pessoal de enfermagem naqueles estabelecimentos, verificou-se que a enfermagem constituiu um elemento fundamental para a implementação do modelo assistêncial asilar, adotado no Brasil.

UNITERMOS: enfermagem psiquiátrica, história oral, ensino

\section{INTRODUÇÃO}

O presente estudo visou à reconstituição histórica das práticas de enfermagem e de preparação para o trabalho desenvolvidas nas instituições psiquiátricas públicas do Rio de Janeiro, Porto Alegre, Salvador, São Paulo e Barbacena no período compreendido entre as décadas de 20 e 50, com o o propósito de revelar a articulação existente entre as formas assumidas por tais práticas e os projetos psiquiátricos implementados em diferentes momentos históricos.

A escolha das práticas de enfermagem como objeto de estudo deve-se à importância que elas assumiram no processo de constituição e consolidação do modelo assistencial asilar, concebido pelos psiquiatras brasileiros no final do século XIX e existente até hoje no país. Como se depreende dos trabalhos de MACHADO et al. (1978); CUNHA (1986); RESENDE (1987); COSTA (1989), desde os primórdíos da organização das instituições e da assistência psiquiátrica no Brasil, coube à enfermagem a realização do cuidado direto aos doentes mentais e a aplicação dos procedimentos disciplinares que possibilitavam sujeitá-los, assim como a manutenção da ordem no interior do espaço asilar.
Contudo, apesar da relevância que os agentes de enfermagem tiveram para a consolidação daquele modelo assistencial, as práticas exercidas por determinados segmentos do pessoal de enfermagem. sobretudo os que não receberam preparo formal em escolas ligadas ao modelo Nightingale, na primeira metade do século XX, praticamente não foram tomadas como objeto de estudo nas pesquisas desenvolvidas na área. Embora tenham constituído importantes fontes secundárias para a presente investigação, as pesquisas empreendidas por FERNANDES (1982); GUSSI (1987); MOREIRA (1990); OGATA (1992), enfocaram fundamentalmente a emergência e a institucionalização do ensino oficial de enfermagem psiquiátrica no Brasil, dando maior ênfase ora à análise do ensino desenvolvido na Escola de Enfermagem Alfredo Pinto - criada em 1890, no Rio de Janeiro-, ora ao implementado na Escola de Enfermagem Anna Nery - fundada em 1923 -, que serviu de modelo para as demais escolas de enfermagem criadas posteriormente no país.

Ocorre que os estabelecimentos de ensino estruturados segundo o modelo Nightingale (do qual a Escola Anna Nery foi precursora) não participaram das experiências de preparação formal e informal de pessoal

* Artigo elaborado com base na tese de doutorado, apresentada ao Curso de Pós-Graduação em saúde Mental do Departamento de Psicologia Médica e Psiquiatria da Faculdade de Ciências Médicas da Universidade Estadual de Campinas, sob orientação da Prof $^{a}$ Dr $^{a}$. Mara Aparecida Alvez Cabral

** Professor Assistente Doutor do departamento de Enfermagem da Faculdade de Ciências Médicas da Universidade Estadual de Campinas 
de enfermagem para trabalhar em hospitais psiquiátricos e em programas de higiene mental, cuja implementação foi intensificada nas décadas de 20 a 40.

De 1890, quando, no Rio de Janeiro, foi criada a primeira escola brasileira destinada à formação de pessoal de enfermagem para atuar no campo da assistência psiquiátrica, até os anos quarenta, tal tarefa foi assumida pelos próprios psiquiatras, em diferentes cidades, seja através da criação de escolas de enfermagem nos próprios estabelecimentos psiquiátricos, seja a partir da implementaçâo de mecanismos informais de preparação no interior do processo de trabalho nas instituições.

Dentre os motivos apontados pelos psiquiatras para se encarregarem da formação dos agentes de enfermagem destacam-se a inexistência de pessoal qualificado para tal ocupação no país e a pretensão de moralizar os trabalhadores que então assistiam às pessoas internadas nas instituições psiquiátricas. Segundo argumentavam FRANCO DA ROCHA (1912); Lisboa apud SOUZA (1942); GODOY (1952); Teixeira Brandâo apud MACHADO et al. (1978); Tourinho apud JACOBINA (1982); Pacheco e Silva apud CUNHA (1986), a maioria das pessoas que procuravam este tipo de trabalho não se submetia às normas disciplinares que deveriam orientar o funcionamento dos asilos para que estes se tomassem efetivamente um local de tratamento para doentes mentais. Aqueles médicos creditavam tal insubordinação às características pessoais dos indivíduos empregados das instituições psiquiátricas, descritos pelos primeiros como imorais, despreparados culturalmente e despossuídos de qualquer vocação para cuidar de doentes mentais. Conforme pensavam FRANCO DA ROCHA (1912); PORTO-CARRERO (1932); MOREIRA (1933); PACHECO E SILVA (193-); GODOY (1952), a qualificação formal ou o preparo informal no interior do próprio processo de trabalho seria uma medida eficaz para especializar enfermeiros de ambos os sexos para cuidar dos doentes mentais nas instituições psiquiátricas e nos programas de higiene mental, segundo os preceitos científicos e humanitários defendidos pela medicina mental brasileira, desde o século XIX.

Como mostram MACHADO et al. (1978); BIRMAN (1978), tais princípios configuravam o chamado Tratamento Moral, que constituía uma prática pedagógica, na qual um conjunto de elementos era manipulado, com a finalidade de levar' o doente a transformar sua conduta estranha e diferente numa atitude de obediência e adaptação à organização asilar. Para tanto, o asilo era estruturado de tal forma que o tempo e o espaço do indivíduo fossem minuciosamente regulados, por um conjunto de agentes (guardas e enfermeiros) hierarquicamente organizados, responsáveis pela vigilância dos internos, sob o comando do psiquiatra. Este ocupava uma posição privilegiada, no topo da hierarquia asilar, centralizando em si a direção técnica e administrativa da instituição, e controlava a movimentação de todos os demais agentes em seu interior. Com isso, pretendia-se que a obediência dos trabalhadores de enfermagem ao alienistas e aos princípios hierárquicos existentes na instituição servissem como exemplo aos pacientes, condicionando seu modo de agir no espaço hospitalar e, por conseguinte, na sociedade.

Conforme MACHADO et al. (1978), tal estruturação do espaço asilar, proposta pelo alienismo francês desde o final do século XVIII e incorporada pela psiquiatria brasileira a partir da segunda metade do século XIX, criou condições para que os hospícios se transformassem num "instrumento terapêutica". Ou seja, em um espaço não só de exclusão social - função que lhes fora atribuída no Brasil, da segunda metade até o final do século XIX-, mas também de produção de um saber sobre a loucura e os meios de curá-la.

As considerações acima embasaram a suposição que originou a presente pesquisa, a saber, a de que os agentes de enfermagem e as práticas por eles desenvolvidas constituíram um elemento fundamental para a transformação dos hospícios num instrumento terapêutica, no período entre o final do século XIX e as primeiras décadas do século XX, dada a importância que os psiquiatras atribuíam à atuação dos guardas e enfermeiros no processo de tratamento do doente mental e à preparação do pessoal de enfermagem que trabalhava naquelas instituições. Todavia, a escassez de fontes primárias escritas, que possibilitassem realizar um estudo sobre tais experiências de preparação e práticas de enfermagem desenvolvidas no campo da assistência psiquiátrica brasileira, entre os anos 20 e 50, com o intuito de confirmar aquela suposição, tornou necessário resgatálas historicamente, mediante o emprego da história oral.

Sendo assim, o objetivo geral da pesquisa foi reconstituir historicamente a formação do saber e das práticas de enfermagem no Brasil desenvolvidas no campo da assistência psiquiátrica no período compreendido entre as décadas de 20 e 50 . E seus objetivos específicos foram: a) identificar os motivos que levaram os sujeitos da pesquisa a trabalhar em enfermagem no campo da assistência psiquiátrica, no referido período; b) reconstruir o processo de preparação do pessoal de enfermagem para trabalhar em instituições psiquiátricas brasileiras, nas décadas de 20 a 50; c) examinar as modalidades de tratamento psiquiátrico empregadas na época e a forma de participação dos agentes de enfermagem na implementação das mesmas, segundo a visão dos sujeitos entrevistados.

\section{METODOLOGIA}

O objeto de estudo foi abordado sob uma 
perspectiva histórica, utilizando-se como método de pesquisa a história oral (ALBERTI, 1989). Na presente pesquisa, a escolha deste método decorreu da necessidade de produzir fontes primárias que permitissem reconstituir a emergência dos agentes e das práticas de enfermagem e os processos de preparação a que estes trabalhadores foram submetidos no Brasil, no campo da assistência psiquiátrica, uma vez que, tal objetivo não poderia ser adequadamente alcançado, somente através da pesquisa documental.

A delimitação do período entre os anos 20 e 50 justifica-se pelos seguintes motivos: 'a) neste período, os hospitais psiquiátricos foram palco para a introdução de diversos tratamentos somáticos e, psicológicos, que aparentemente substituíram o chamado tratamento moral, predominante até os anos 20 deste século, e para o surgimento de novas proposições de atendimento, voltadas para a prevenção da doença mental (os Programas de Higiene Mental). Isto, supostamente, produziu transformações na assistência de enfermagem e na organização de seu processo de trabalho, demandando profissionais mais qualificados; b) desde os anos 20, houve um recrudescimento das iniciativas voltadas para a preparação formal de pessoal de enfermagem, tanto na área de psiquiatria, quanto na de saúde pública; c) só seria possível encontrar testemunhas vivas e em condições de relatar suas memórias, a partir da década de 20 .

O critério utilizado para definir os locais onde foi realizada a pesquisa de campo foi a cronologia de criação dos hospitais psiquiátricos públicos e das primeiras escolas de enfermagem brasileiras, a saber: Centro Psiquiátrico Pedro II (antiga Colônia de Psicopatas do Engenho de Dentro, 1923), Colônia Juliano Moreira (antiga Colônia de Psicopatas de Jacarepaguá, 1924), Escola de Enfermagem Alfredo Pinto, UNIRIO (1890); Escola de Enfermagem Arma Neiy, UFRJ (1923); no Rio de JaneiroRJ. Hospital do Juqueri (1895), em Franco da Rocha; Instituto de Psiquiatria da USP (1945), Escola de Enfermagem da USP (1942), em São Paulo-SP. Hospital Psiquiátrico São Pedro (1884), Escola de Enfermagem da UFRS (1950), em Porto Alegrc-RS. Hospital Psiquiátrico Juliano Moreira (1874), Escola de Enfermagem da UFBA (1946), em Salvador - BA. Centro Hospitalar Psiquiátrico de Barbacena (19O3) e a Escola de Enfermagem da UFMG (1933), em Belo Horizonte-MG. Esta última instituição foi excluída no decorrer da pesquisa de campo, pois verificou-se que a parte prática do ensino de enfemagem psiquiátrica não era realizada no Hospital de Barbacena.

No período de janeiro de 1991 a outubro de 1992, foram feitos os contatos com os dirigentes dos estabelecimentos psiquiátricos e de ensino mencionados acima, com o intuito de obter autorização para consultar os arquivos das instituições. Uma vez autorizada, a pesquisadora dirigia-se àqueles locais e iniciava a pesquisa de campo, que consistia no levantamento dos documentos pertencentes ao acervo(quando existia) de cada instituição e num levantamento de nomes e endereços de antigos funcionários, médicos ou da enfermagem, no Departamento Pessoal. Quando este levantamento era prejudicado pela má conservação dos arquivos ou pelo extravio de fichas, o que ocorreu com bastante frequência, recorria-se aos funcionários mais antigos em exercício na instituição. Estes forneciam os nomes e endereços de colegas aposentados, cujas características preenchiam os critérios estabelecidos para seleção dos sujeitos da pesquisa, que eram os seguintes: a) ter participado dos processos de preparação de pessoal de enfermagem para trabalhar em psiquiatria, ou como aluno, ou como professor, no período de 20 a 50; b) ter trabalhado no setor de enfermagem, ou como médico, no referido período, nas instituições selecionaras c) ter ingressado no hospital, naquele período. d) apresentar condições de saúde que lhe permitissem realizar a entrevista; e) disponibilidade do entrevistado para relatar sua experiência profissional.

Assim, foram localizados um total de cinquenta e sete informantes, dos quais quarenta e nove concordaram em gravar seus depoimentos. Como instrumento, foi utilizado um roteiro geral de entrevista, semi-estruturado, composto de onze perguntas abertas (Anexo 1).

Durante a entrevista, procurava-se estabelecer com o entrevistado um clima de confiança para que pudesse relatar livremente suas experiências e fazer associação de idéias, sem que houvesse uma preocupação em obedecer rigidamente a ordem das perguntas do roteiro. Assim, favorecia-se ao informante a possibilidade de avançar ou retroceder no relato de suas experiências, conforme julgasse necessário para esclarecer sua visão sobre os diferentes temas abordados.

Uma vez concluída a pesquisa de campo em cada cidade, a pesquisadora retornava à Campinas. onde os relatos orais eram cuidadosamente transcritos e os documentos coletamos nos arquivos das instituições (regimentos internos, regulamentos, artigos científicos, artigos de jornais, dentre outros) eram devidamente classificados.

Passava-se, então, à análise dos depoimentos. Primeiramente, cada relato transcrito era submetido a uma leitura minuciosa, com o intuito de apreendê-lo em sua totalidade. A seguir, realizava-se o fichamento de cada depoimento por temas. Numa etapa posterior, os depoimentos eram submetidos a uma nova classificação, na qual os trechos de cada relato, correspondentes aos diferentes temas abordados, eram reunidos aos demais, o que possibilitava comparar as várias versões dos informantes sobre um mesmo tema. Procurava-se, então, 
distinguir semelhanças e diferenças entre as versões produzidas pelos sujeitos sobre um mesmo fato ou período histórico relatado. Paralelamente, comparavamse as informações fornecidas nos depoimentos com os dados obtidos durante a pesquisa documental. A seguir, estabelecessiam-se os nexos entre este conjunto de dados e o contexto histórico em que foram produzidas aquelas versões.

Deste modo, foi possível reconstituir diferentes aspectos relacionados ao cotidiano das práticas de enfermagem no interior das instituições psiquiátricas examinadas e proceder à discussão teórica dos elementos que nelas estavam implicados. A seguir, destacam-se algumas questões abordadas ao longo do trabalho.

\section{A ORGANIZAÇÃO DA ASSISTÊNCIA PSIQUIÁTRICA NO BRASIL, NO PERÍODO DE 20 A 50}

No Brasil, a loucura e o louco só passaram a representar um problema para a medicina e para o Estado brasileiro a partir da primeira metade do século XIX. Desde então, ambos adquiriram o estatuto de objeto da prática médica e de intervenções estatais. As primeiras instituições especificamente destinadas à exclusão social do louco surgiram a partir da segunda metade do século XIX (MACHADO et al., 1978; CUNHA, 1986; RESENDE, 1987).

Todavia, uma intervenção sobre a loucura, baseada num saber eminentemente médico e numa concepção do que deveria ser um asilo para alienados, sob tal ponto de vista, só seria alcançara no final do século XIX. Neste período, com o intuito de implementar seu projeto de transformação dos hospícios num espaço terapêutica, os médicos travaram uma verdadeira batalha, tanto internamente, quanto externamente aos muros daquelas instituições(.MACHADO et al., 1978; CUNHA, 1986; RESENDE, 1987). No interior dos hospícios existentes no país, acirraram-se os conflitos entre os alienistas, os agentes de enfermagem (fossem leigos ou religiosos) e os responsáveis pela administração daqueles estabelecimentos (ligados às congregações religiosas que geriam as Santas Casas de Misericórdia), que até então detinham o poder sobre a vida dos loucos no cotidiano do espaço asilar. Tais confrontos culminaram na centralização do poder técnico e administrativo nas mãos dos alienistas e na sujeição dos agentes de enfermagem ao poder médico. Esta foi obtida mediante a implementação de um rígido controle sobre a força de trabalho em enfermagem, graças à operacionalização de um conjunto de procedimentos disciplinares, expressos em instrumentos jurídicos que regulavam a vida asilar (regimentos, regulamentos), e à criação de mecanismos formais ou informais de preparação do pessoal de enfermagem, que possibilitaram a transformação definitiva do asilo num instrumento de intervenção tipicamente médico sobre a loucura.

O contexto econômico, político, social e cultural em que se encontrava o país naquele momento histórico, contribuiu decivamente para que isso acontecesse, pois a concentração do poder técnico e administrativo nas mãos dos alienistas só pôde ser obtido em função das articulações políticas existentes entre estes e os grupos sociais que adquiriram a hegemonia no interior do Estado, através da constituição do regime republicano (MACHADO et al., 1978; JACOBINA, 1982; CUNHA, 1986; RESENDE, 1987).

No período compreendido entre a última década do século passado e a primeira década do século XX o processo de organização da assistência psiquiátrica, sob a direção dos psiquiatras, intensificou-se em várias capitais e cidades brasileiras. No Rio de Janeiro, Porto Alegre, Salvador, São Paulo e Barbacena, por exemplo, sobretudo nos anos 10, observa-se uma expansão numérica dos estabelecimentos e dos leitos psiquiátricos, decorrente da criação dos hospitais colônia, ou de colônias agrícolas ligadas aos hospícios ou da ampliação do número de pavilhões nos hospitais já existentes (RESENDE, 1987). Este crescimento foi vislumbrado pelos psiquiatras como um meio de responder a alguns dos problemas que eles identificavam como um entrave à melhoria da assistência psiquiátrica. Dentre eles, citavam a superlotação e a deterioração dos pavilhões dos hospitais então existentes; das quais decorriam as dificuldades para aprofundar a sistematização das classificações nosográficas e aprimorar os meios de tratamento, que, segundo os psiquiatras, inviabilizavam cada vez mais a separação dos internados, segundo o sexo, a idade, a patologia, o prognóstico (crônicos ou agudos), condição necessária à implementação do tratamento moral. Porém, com o crescimento dos hospícios e das colônias, outras dificuldades colocaram-se aos alienistas. Uma deles foi a falta crônica de recursos financeiros para manutenção dos hospitais. Outra, foi a carência de força de trabalho em enfermagem devidamente qualificada para assistir aos doentes mentais, conforme os preceitos da psiquiatria. Em cada um daqueles locais, os psiquiatras lançaram mão de distintas estratégias para atenuar tal problema. No Rio de Janeiro, por exemplo, em 1905, trataram de reativar a escola anexa ao Hospício Nacional de Alienados (MOREIRA, 1990). Em São Paulo, Franco da Rocha tentou organizar uma escola de enfermagem no Hospital do Juqueri, em 1910 (FRANCO DA ROCHA, 1912), mas não há registros de que esta iniciativa tenha sido levada adiante. Em Porto Alegre, o diretor do Hospital São Pedro contratou um grupo de irmãs de caridade francesas, que assumiram o serviço de enfermagem naquela instituição em 1910 (Lisboa apud SOUZA, 1942; 
GODOY, 1952).

Segundo CUNHA (1986); RESENDE (1987); COSTA (1989), nas décadas de 20 e 30, observa-se uma intensa movimentação no campo da assistência psiquiátrica no país, que esteve diretamente relacionada com as tranformações por que vinha passando o Estado e a sociedade brasileira neste período. Trata-se de um momento histórico marcado pela publicação de sucessivos decretos federais e estaduais que reorganizam a assistência psiquiátrica, ora visando ampliar o número de hospitais psiquiátricos públicos; ora disciplinando as relações de trabalho entre os diferentes agentes que atuavam no interior do espaço asilar; ora organizando escolas de enfermagem nas próprias instituições psiquiátricas, como ocorreu, por exemplo, no Rio de Janeiro e em Porto Alegre. Nos anos 30, ocorre ainda uma maior centralização administrativa, mediante a criação de órgãos centrais, aos quais passam a se subordinar os diversos estabelecimentos psiquiátricos distribuídos pelos estados e distrito federal. A coordenação de tais órgãos passa a ser atribuída exclusivamente aos psiquiatras. Além disso, nos anos 20 e 30, assiste-se ao surgimento de uma produção científica nacional, na área da psiquiatria; à descentralização do processo de formação de psiquiatras, papel até então ocupado quase que exclusivamente pelos psiquiatras do Hospício Nacional de Alienados, do Rio de Janeiro; ao desenvolvimento das pesquisas anatomopatológicas nos hospitais públicos do Rio de Janeiro, São Paulo e Porto Alegre; e à introdução das terapias orgânicas nas três instituições (ROXO, 1944; PACHECO E SILVA, 1945; GODOY, 1952; UCHÔA, 1981; RESENDE, 1987).

Este momento, foi marcado também pela criação dos primeiros ambulatórios e Programas de Higiene Mental, que, inicialmente, foram concebidos como uma estratégia para atenuar o problema da superlotação crescente dos hospitais, através da diminuição do número de intemações psiquiátricas. Mas, a partir dos anos 30, os psiquiatras do Rio de Janeiro e São Paulo, consideraram tais medidas insuficientes e lançaram-se num projeto que visava não só a organização de serviços extramurais, mas também a extensão do objeto de intervenção da psiquiatria, mediante a detecção precoce das doenças mentais. Conforme assinalam CUNHA (1986); COSTA (1989), em tal perspectiva, supostamente preventiva, o objeto da psiquiatria deixou de ser constituído exclusivamente pelo doente mental e passou a ser a sociedade, particularmente o segmento constituído por setores da classe operária, nos quais estavam incluídos os imigrantes estrangeiros e os negros, o que transformou os programas de higiene mental num instrumento de difusão de concepções xenófobas, racistas e antiliberais. De acordo com o que se verificou nesta pesquisa, embora não seja possível afirmar que tal concepção fosse compartilhada por todos os psiquiatras que se engajaram na organização dos programas e ambulatórios de higene mental em diversos locais do Brasil, é interessante ressaltar que a adoção de tais estratégias não se limitou ao Rio de Janeiro e São Paulo, mas estendeu-se também aos outros locais, tais como Porto Alegre, Barbacena e Salvador, nos anos 40 e 50.

Em certos locais, a inexistência de pessoal de enfermagem formalmente qualificado levou os psiquiatras a empreenderem determinados processos de preparação que visavam à formação de agentes de enfermagem para participar da implementaçâo destes programas. Segundo se verificou, tal medida foi posta em prática no período de 20 a 40, no Rio de Janeiro, onde foi organizado o curso de visitadoras sociais da Escola de Enfermeiras Alfredo Pinto, e durante os anos 40, em Porto Alegre, onde os alunos da Escola de Enfermagem do Hospital São Pedro recebiam treinamento para trabalhar no chamado Serviço Aberto.

No entanto, não se pode afirmar que, na prática, as propostas que visavam à diminuição do número de internações psiquiátricas e à melhoria da assistência psiquiátrica tenham alcançado seus objetivos, dada a intensa deterioração dos estabelecimentos psiquiátricos públicos nos anos 40 e 50 e dado o crescimento das internações e da população dos mesmos até o final dos anos 50, observado por RESENDE (1987); CERQUEIRA(1989).

\section{OS MOTIVOS QUE LEVAVAM O PESSOAL DE ENFERMAGEM A INGRESSAR NOS HOSPITAIS PSIQUIÁTRICOS BRASILEIROS, NO PFRÍODO DE 20 A 50}

Nas primeiras décadas do século XX, o trabalho de enfermagem nos hospitais psiquiátricos era cercado de preconceitos, seja por ser associado ao trabalho manual, seja por ser visto pelas pessoas como uma atividade degradante e insalubre, devido à agressividade que supostamente caracterizava os doentes mentais, à superlotação e às condições de deterioração em que se encontravam tais instituições. Além disso, como já foi dito, os dirigentes daquelas instituições tinham uma visão desfavorável dos trabalhadores que procuravam este tipo de ocupação e acreditavam que estes o faziam somente por não conseguirem se empregar em outras atividades.

Julgavam que tal situação decorria dos baixos salários oferecidos, mas, apesar disso, reclamavam da dificuldade de encontrar pessoas que tivessem aptidão ou vocação para lidar com os doentes mentais, além de outras qualidades, que psiquiatras como PORTOCARRERO (1932); MOREIRA (1933); GODOY (1952) 
julgavam fundamentais para este tipo de atividade, tais como: paciência, doçura, intercaladas com energia e firmeza de caráter. Tal visão pouco modificou-se no período de 20 a 50. Mas, essa é a versão dos dirigentes.

$\mathrm{O}$ exame da versão produzida pelos próprios agentes de enfermagem indica que os motivos que os levaram a trabalhar em psiquiatria estiveram relacionados ao contexto social, econômico e cultural em que estavam inseridos, bem como revela distintos aspectos que permeavam a vida daquelas pessoas, as representações sociais que tinham sobre este tipo de trabalho e as particularidades que apresentavam os processos de seleção nas instituições psiquiátricas no período em estudo. A seguir, discute-se algumas das questões abordadas no trabalho.

Conforme mostram os depoimentos dos entrevistados que ingressaram nos estabelecimentos psiquiátricos do Rio de Janeiro, no período compreendido entre as décadas de 20 e 30 , um emprego em enfermagem podia representar não só um meio de sobrevivência, mas também uma alternativa de profissionalização, numa época em que o mercado de trabalho formal era restrito (RIBEIRO, 1986) e em que as oportunidades educacionais eram extremamente limitadas para os indivíduos oriundos das classes trabalhadoras, sobretudo para as mulheres SAFFIOTI, 1976).

Extraído do depoimento de uma ex-aluna da seção feminina da Escola Alfredo Pinto, que ingressou na Colônia do Engenho de Dentro em 1920, o trecho reproduzido abaixo exemplifica a primeira situação, em que a procura pelo emprego foi determinada, em primeira instância, pela necessidade de sobrevivência:

"Eu cheguei (de Minas Gerais) no Rio de Janeiro, porque perdi minha mãe. Morava com uma família que era muito amiga da Diretora da Colônia. (..) Então, ela foi lá (em casa) e eu pedi se podia trabalhar. "Você ? Muito menina"(disse a diretora). Com quinze anos que eu comecei a trabalhar. Ela disse: "Está bem. Eu vou levar para eles para ver se você dá". "Eu tinha mesmo muita vontade de trabalhar e fiquei seis meses sem ganhar nada. Só para casa e comida(...) Daí, eu fiquei. Comecei a ganhar 30 mil réis. (..) Fiquei trabalhando lá como guarda; depois eu fui para a enfermaria.(...) Aí foi que o Gustavo Riedel entrou, o diretor, e quis abrir a escola de enfermagem. Então (ele) disse: "Se você não quiser estudar, você vai ser rebaixada e para o seu lugar vai vir uma diplomada". Eu, então, fui obrigada a estudar e fui para a escola. Estudei quatro anos, não é ? Como enfermeira".

A fala acima, chama a atenção para o fato de que, na maioria das vezes, o ingresso no hospital psiquiátrico não constituía propriamente uma escolha profissional pela especialidade, mas tomava-se uma possibilidade de obter um emprego, em função da rede de relações sociais em que o sujeito se encontrava inserido. Entretanto, esta situação não é singular e reaparece mesmo nos casos em que a procura por trabalho em uma instituição psiquiátrica era vista não só como uma forma de garantir a sobrevivência, mas também como uma alternativa de profissionalização, conforme se vê a seguir:

"(Fui trabalhar na Colônia de Psicopatas), porque eu morava praticamente ao lado (da Colônia do Engenho de Dentro), (...). E eu queria uma profissão, já estava com 21 anos, em casa. Tinha terminado meus cursos, antes e tudo, e não tinha profissão definida, então eu queria uma profissão. Fui encaminhada para lá, sabe ? Cheguei lá, falei com o pessoal. Foi por isso que eu fui ser enfermeira. Fiz um concurso."

Pela análise dos depoimentos, foi possível verificar que, para as mulheres oriundas da classe trabalhadora, a enfermagem era percebida como um meio de melhoria de suas condições de vida. Com a criação das escolas de enfermagem, esta ocupação adquiriu uma certa valorização social, tomando-se uma alternativa de profissionalização não só para as mulheres que pertenciam às classes dominantes - que constituíam a clientela da Escola Anna Néry e da Escola da Cruz Vermelha, criada em 1916, como ressalta SILVA (1986) - mas também para as que provinham das classes trabalhadoras - população absorvida pela Escola de Enfermagem Alfredo Pinto, dos anos 20 aos anos 30. Além disso, estas percebiam este tipo de atividade não como um trabalho manual. mas como um trabalho intelectual, pelo fato de sua realização exigir uma formação obtida mediante escolarização específica.

Diferentemente daquelas informantes, para os sujeitos que ingressaram nos estabelecimentos psiquiátricos públicos de São Paulo, Porto Alegre, Salvador e Barbacena, no período compreendido entre o final dos anos 30 e a década de 50, a procura por um emprego naquelas instituições foi motivada exclusivamente pela necessidade de sobrevivência econômica. Segundo um destes entrevistados diz:

“ Olha, leigo, sem conhecimento nenhum, eu nem sabia o que era doente mental E entrei simplesmente porque eu precisava de um emprego. E naquela época era tudo; aquelas pessoas que procuravam o hospital, não era por um ideal ou... mas simplesmente pela necessidade de trabalhar.

E foi como eu ingressei, no dia 21 de fevereiro de 1939. (...) “

Para os trabalhadores de ambos os sexos, que não possuíam qualquer qualificação formal, fosse em enfermagem fosse em outro tipo de ocupação, o emprego público garantia-lhes um regime de trabalho diferente do 
adotado nas atividades do setor primário e secundário da economia (RIBEIRO, 1986), tais como : assistência médica gratuita, aposentadoria e estabilidade no emprego. Além disso, num período em que o mercado de trabalho brasileiro caracterizava-se pelo crônico subemprego de grandes contingentes da população economicamente ativa (SAFFIOTI, 1976), o ingresso nos hospitais psiquiátricos possibilitava àqueles trabalhadores usufruir de vantagens, como, por exemplo, alimentação ou moradia gratuita no próprio local de trabalho, que dificilmente encontrariam em outras instituições. Estas condições de trabalho tinham um peso importante na procura por este tipo de ocupação, conforme se lê abaixo:

"Na época da (segunda) guerra, era muito difícil arrumar emprego. Então, eu vim de Minas para cá. Fiqueí em São Paulo, meio jogado para lá, para cá... Não tinha muito emprego e, naquela época, os jornais pediam funcionários para cá. Naquela época não se chamava funcionário, era guarda. Guarda para o Hospital do Juquepi. Era 150 por mês, livre de cama, bóia (alimentação) e lavagem de roupa. Então eu falei: "Bom, o negócio é carregar minhas tralhas, vamos embora' Aí, eu peguei e vim para cá."

"Eu vim porque eu tinha seis filhos pequenos. Eu trabalhava na fábrica, mas teve uma época que as fábricas começaram a mandar todo mundo embora. Eu estava esperando uma menina e eles me mandaram embora. E eu, toda a vida, fui desse tipo de não saber ficar parada, e vi os filhos precisando das coisas ... Aí, eu linha pedido para o Dr. para arrumar para mim (...)Então saiu (a contratação).

"Na época, em 53, eu tinha 23 anos. E eu, até, era mecânico, não é? Mas, eu tinha vontade de ter um emprego mais certo. Então, naquele tempo, você entrava no hospital através de política(..)Não era concurso, era nomeação. Então, eu fui. Fiz um estágio no Hospital-Colônia de março até julho. E, chegou em julho, eu fui nomeado mesmo... “

Segundo mostram os depoimentos, naquela época, o empreguismo e o apadrinhamento eram um outro elemento que caracterizava o ingresso do pessoal de enfermagem nas instituições psiquiátricas, o que significa que, na prática, as qualidades pessoais do trabalhador de enfermagem, tão propugnadas pelos psiquiatras em seus escritos, eram preteridas em função de certas prerrogativas.

Apesar da necessidade de sobrevivência também ser apontada para justificar a opção pelo trabalho em enfermagem psiquiátrica, nota-se que, entre as enfermeiras formadas por escolas de enfermagem ligadas aos estabelecimentos de ensino superior de São Paulo, Minas Gerais, Bahia e Rio Grande do Sul, na década de 50, a escolha desta atividade foi motivada, predominantemente, por uma identificação com a especialidade. Dentre os motivos que, segundo as informantes, favoreceram tal identificação, verifica-se: a influência de professores, durante o curso de enfermagem, o contexto familiar e a inclinação ou vocação para aquele tipo de trabalho. Em seus relatos, elas diziam:

'(.. ) E um dos estágios que eu fiz foi em enfermagem psiquiátrica. Todas as coisas que não tinham campo em Juiz de Fora eram feitas em outros lugares. Lá, na escola de São Paulo, íamos fazer a parte prática em Franco da Rocha. Foi, mais ou menos. em 1950. (..) Eu gostei do estágio. Era uma coisa horrorosa. mas de todas as alunas fui a que mais gostei. Porque vi que era eu a que menos se assustava.

"Quando terminei, a nossa turma foi fazer estágio em psiquiatria em São Paulo, um estágio prático. Eu fiz a psiquiatria teórica toda aqui (em Salvador). Então, eu adorava psicologia, psiquiatria, tudo o que fosse essas coisas assim, lá de cima, eu adorava e me saía muito bem nisso, não é?(..) Psiquiatria foi o meu sonho. “

"Meu pai era médico e, no tempo dele não havia especialidade tão caracterizada como hoje. Mas, ele trabalhou no Hospital Juliano Moreira, entendeu? Não sei se isso teria tido uma influência meio inconsciente. Eu sempre fui uma pessoa muito voltada para conhecer as pessoas, sempre me fascinou isso: porque as pessoas se comportam de tal maneira? Desde adolescente eu gostava de ouvir, conversar, conhecer. (.) Depois eu quis fazer psicologia, no tempo em que não existia psicologia (em Salvador). Fiz vestibular, passei. Adorei o curso de enfermagem. (..)E, aí, veio, quer dizer, eu já tinha uma tendência, e veio uma pessoa que realmente me ajudou a decidir, que foi Teresa Sena. Ela dava aquelas aulas maravilhosas, e do convívio que eu tive com Teresa, eu já me inclinei. Então, o destino é esse. Eu, com essa inclinação que tinha (..) “

Note-se que as entrevistadas apontam "tendências", "inclinações", o gostar de psiquiatria e disciplinas afins como um dos motivos que as levou a optar por tal especialidade. Conforme explica MELLO (1982), geralmente, tais colocações são feitas por pessoas cujas condições de vida e origem social propiciaram-lhes maior possibilidade de escolha profissional e escamoteiam o fato de que estas opções são possibilitadas pelas condições materiais de existência a que os sujeitos estão submetidos e não somente por seu desejo pessoal. Com efeito, observou-se que as enfermeiras entrevistadas provinham predominantemente das classes médias urbanas e, ou tinham grau de escolaridade secundário, ou haviam cursado a Escola Normal. A despeito das restrições à participação das mulheres no mercado de 
trabalho, existentes naquela época, a origem social e o grau de escolaridade das informantes possibilitaram-lhes aspirar às profissões de maior prestígio na hierarquia das chamadas profissões femininas, dentre as quais situavase a enfermagem - realizada nas escolas ligadas aos estabelecimentos de ensino superior (SAFFIOTI, 1976)). E, também, permitiu-lhes fazer escolhas profissionais com relativa liberdade, diferentemente do que acontecia com os demais agentes de enfermagem que provinham das classes trabalhadoras, para os quais esta possibilidade praticamente não se colocava.

\section{AS MODALIDADES DE PREPARAÇÃO DO PESSOAL DE ENFERMAGEM PARA IMPLEMENTAR OS PROJETOS PSIQUIÁTRICOS NAS INSTITUIÇÕES BRASILEIRAS NO PERÍODO DE 20 A 50}

A necessidade de formar enfermeiros para prestar cuidados aos doentes mentais, baseados em princípios científicos, constituiu um tema frequente no discurso dos dirigentes dos hospitais psiquiátricos brasileiros nas décadas de 20 a 50. Entretanto, a importância atribuída a tal questão nos discursos nem sempre redundou em iniciativas concretas, haja visto que a organização de escolas destinadas à preparação de pessoal de enfermagem para aquelas instituições ocorreu apenas no Rio de Janeiro e em Porto Alegre, não se generalizando para outros locais, naquele período.

A partir da reconstituição histórica dos processos de preparação de pessoal. implementados no Rio de Janeiro, Porto Alegre, São Paulo, Salvador e Barbacena, verificou-se que tais experiências assumiram formas diversificadas em cada local e em distintos períodos históricos. Observou-se que existiam fundamentalmente duas modalidades de preparação: uma, por meio do ensino formal, na qual o conteúdo era organizado de forma sistematizada, através de urn currículo. Outra, a partir da educação informal, em que o indivíduo aprendia a cuidar do doente em seu próprio local de trabalho, a partir da assimilação de normas e formas de abordar o paciente que eram transmitidas oralmente no cotidiano do processo de trabalho pelos diferentes agentes que atuavam no espaço asilar (trabalhadores de enfermagem ou psiquiatras). No entanto, muitas vezes, os dois modos de preparação ocorriam ao mesmo tempo, no interior de uma mesma instituição.

No âmbito deste artigo, enfocar-se-á somente a primeira modalidade de preparação, adotada no Rio de Janeiro e em Porto Alegre, no período de 20 a 50. Nestes locais, em meio ao processo de reorganização da assistência psiquiátrica, empreendido nos anos 20, deuse a reestruturação da Escola Profissional de Enfermeiros e Enfermeiras, anexa ao Hospício Nacional de Alienados, em 1921 (MOREIRA 1990), e a criação da Escola Profissional de Enfermagem Especializada do Hospital São Pedro, em 1925, que, no entanto, só passaria a funcionar efetivamente em 1939 (GODOY, 1952). Em 1921, no regimento interno da primeira, foi estabelecida sua divisão em três seções: uma seção mista, uma feminina e uma masculina. Destas, somente as duas primeiras foram postas em funcionamento, tendo sido mantida a seção mista no Hospício Nacional, enquanto a segunda foi transferida para uma nova sede, na recém inaugurada Colônia de Psicopatas do Engenho de Dentro, passando a chamar-se Escola Profissional de Enfermeiras Alfredo Pinto (MOREIRA, 1990). Na escola do Hospital São Pedro, o ensino era misto. Tanto nesta, quanto nas escolas do Rio de Janeiro, a duração do curso era de dois anos, com caráter terminal. Na Escola Alfredo Pinto, em 1927, ao curso de enfermagem foi acrescido um terceiro ano, ao final do qual as alunas da seção feminina recebiam o diploma de visitadora social. Tais cursos visavam à formação de pessoal de enfermagem para atuar nos hospitais psiquiátricos, nos ambulatórios e nos programas de higiene mental, citados anteriormente.

Havia uma forte semelhança nos currículos adotados naquelas escolas. Observou-se que os mesmos contemplavam as transformações por que vinha passando o saber psiquiátrico naquele período. Marcado pela psiquiatria organicista e pela higiene mental, que gradativamente foram ocupando o lugar até então hegemônico do tratamento moral na prática psiquiátrica, tal saber objetivava-se não só no currículo formal, mas, principalmente, no conteúdo desenvolvido durante as aulas teóricas e práticas, ministradas no interior dos próprios serviços. Nestas, havia uma ênfase nos estudos anatomopatológicos, na farmacologia, na higiene, assim como nas práticas de análises clínicas, que instrumentalizavam as intervenções dos psiquiatras naquele período. Segundo os entrevistados do Rio de Janeiro, nos anos 20 e 30, o conteúdo desenvolvido não se restrigia ao aprendizado dos procedimentos empregados no tratamento moral, mas:

“(...) aprendia-se de tudo, sendo que a cadeira de psiquiatria tinha que fazer um tanto lá (no Hospício Nacional), um tanto aqui (na Colônia Juliano Moreira). Nós tínhamos um enfermeiro, lá no Pavilhão Pinel, que antigamente eles faziam uma injeção na medula do camarada ... Era para tirar o líquor da espinha.

"Na Colônia do Engenho de Dentro, nós tínhamos a especialidade de otorrinolaringologia. $O$ professor era o Dr. Gastão Guimarães. Ele trabalhava no ambulatório e nós acompanhávamos eles também. A gente tinha estágio no ambulatório, tinha uma enfermaria pequena, onde fazia-se cirurgia (...) E nós 
acompanhávamos".

O processo sistematizado de preparação contribuía para constituir uma força de trabalho mais compatível com as necessidades das instituições psiquiátricas, na medida em que possibilitava, ao mesmo tempo, a aquisição do saber psiquiátrico sobre a loucura e suas formas de tratamento e a introjeção das normas disciplinares que regiam o cotidiano asilar. A assimilação da concepção médica da loucura como doença mental e do louco enquanto indivíduo incapaz, cujo comportamento poderia ser comparado ao das crianças (B, 1978), assim como das formas de lidar com o paciente, respaldadas nos princípios que sustentavam o tratamento moral, acontecia no decorrer do processo de formação, conforme se depreende dos trechos reproduzidos abaixo:

"Ensinavam os tipos de doenças, os tratamentos, o que a gente tinha que fazer. No meu tempo, não podia chamar de maluca, tinha que ser doente mental “

"Só ensinavam que a gente tivesse paciência, que visse elas como doentes, como crianças. Tivesse muita paciência, mas, ao mesmo tempo, energia, para eles não tomarem liberdade.(.) Eles ensinavam que quando a gente percebesse que elas estavam ficando alteradas era para levar para uma sala e cuidar delas bem. Não podia bater. A gente podia apanhar, mas bater não (ênfase). E o Dr. Gustavo e a Dona Albertina não consentiam nada disso. Não se podia fazer nada. A gente podia apanhar, mas nunca bater".

Nos anos 40, a transmissão da concepção dos psiquiatras sobre o doente mental ainda permeava o ensino de enfermagem implementado pelos psiquiatras, conforme mostra um ex-aluno da Escola Profissional do Hospital São Pedro:

"Eu trabalhei como atendente de 1939 até 1948. Em 1948, o falecido Dr. Jachinto Godoy preparava as pessoas para ingressarem, para fazer o curso de Enfermagem. Então, comecei a aprender o que é doença mental porque até então eu sabia que era um ser humano, mas não sabia, assim, como se podia manejar esta criatura... Porque não linha ensinamento. Então, aí, comecei a saber tratar o doente como um paciente mesmo, o que é que eu representava para ele dentro de um hospital psiquiátrico. Então, aí começou a minha vida profissional propriamente dita".

Durante o processo de preparação, a introjeção das normas que regiam o cotidiano asilar era favorecida pelo emprego de um conjunto de procedimentos disciplinares (FOUCAULT, 1977), tais como a distribuição dos alunos no espaço, o controle do tempo de cada indivíduo e a vigilância hierárquica. Conforme recordam as entrevistadas, que moravam no internato da Escola, na Colônia do Engenho de Dentro:
"Nós acordávamos às sete horas e íamos tomar café no pavilhão. As externas chegavam às oito horas. Aí, eram distribuidas por seus respectivos lugares. Cada uma ía para o lugar que estava destinada. Quando chegava na hora do almoço, a gente vinha e almoçava, e as aulas, então, eram depois do almoço (... )".

Nas escolas do Rio de Janeiro, a distribuição dos alunos pelos pavilhões ficava a cargo das enfermeiras, chamadas inspetoras, a quem cabia a vigilância dos mesmos e a manutenção da disciplina na instituição. As inspetoras eram recrutadas entre as próprias alunas, que assumiam a vigilância das colegas mais novas. Mas, além destas funções, elas também tinham uma participação no ensino prático, como explica uma entrevistada:

"Os médicos davam a teoria, mas a prática era com elas. Eram enfermeiras formadas pela Alfredo Pinto. E elas ensinavam a gente a fazer curativos, a lidar com os doentes e coisas assim".

A incorporação de regras e de princípios como obediência e respeito à hierarquia e à autoridade do médico também era propiciada pelo processo de preparação formal, através do emprego de outros mecanismos disciplinares indicados por FOUCAULT (1977), tais como, a sanção normalizadora e o exame. As situações descritas nos trechos abaixo exemplificam o uso de tais instrumentos no processo de formação empreendido na escola portoalegrense:

"Toda a enfermagem prática do primeiro ano era dada por ele (psiquiatra). Tudo; inclusive ele estava sempre presente. Não era só ensinar, ele fazia. Na prova prática, ele estava junto contigo para ver se tu tremias para fazer uma injeção endovenosa... Eu sabia tanto, que protestei quando ele me deu nota 7. Eu disse a ele: 'Mas, eu sei.'(E ele respondeu): 'Mas, tu não ganhas mais do que isso, porque 10 é só para mim, senão tu sabes mais do que eu. Eu não te dou dez. 'Mas, então, eu tirei o primeiro lugar e, por isso, tem até o meu retrato num quadro do Hospital São Pedro".

"A Neurologia, eu nunca posso me esquecer que o Dr. Escobar me tirou um ponto; ao invés de me dar 10, me deu nove, porque eu levei uns dois ou três minutos para me lembrar de onde partia o Sistema Nervoso Central".

Observou-se que a sanção normalizadora e o exame eram instrumentos permanentemente utilizados não só na escola do Hospital São Pedro, mas também na Escola de Enfermeiras Alfredo Pinto e na Seção Mista da Escola Profissional de Enfermeiros e Enfermeiras do Hospício Nacional, no período em estudo. Graças ao emprego destes mecanismos, que correspondiam a um verdadeiro ritual de poder, era possível aos psiquiátras reafirmar ininterruptamente sua posição superior na hierarquia da instituição e a relação intrínseca entre saber 
e poder, objetivada na autoridade dos professores. De outro lado, tais mecanismos viabilizavam a qualificação e a quantificação do comportamento e do conhecimento de cada pessoa, permitindo classificá-la segundo uma graduação hierárquica (primeiro, segundo, terceiro lugar e daí por diante), com base na qual estabeleciam-se as promoções no interior do processo de formação e a posição que o aluno ocuparia ao sair da escola. E, finalmente, seu emprego permitia ainda punir os indivíduos pelos menores desvios cometidos e pressionava-os a submeterem-se a um mesmo modelo, no qual era "obrigados todos juntos à subordinação, à docilidade, à atenção nos estudos e nos exercícios, e à exata prática dos deveres e de todas as partes da disciplina" (FOUCAULT, 1977). Com isso, obtinha-se a uniformização dos trabalhadores, tão cara à implementação do modelo assistencial asilar.

\section{CONSIDERAÇÕES FINAIS}

O estudo empreendido teve como objetivo geral reconstituir a história das práticas de enfermagem no campo da assistência psiquiátrica no Brasil e sua articulação com o projeto psiquiátrico de transformação do hospício num instrumento terapêutica, que culminou com a constituição do modelo assistencial asilar, até hoje existente no país. Tratou-se, aqui, da discussão de alguns aspectos que contribuíram para que os agentes de enfermagem constituíssem um elemento fundamental para os psiquiatras atingirem aquele propósito. Deste modo, verificou-se que, ao longo da trajetória de medicalização da loucura e do louco e sua conseqüente exclusão social nos hospícios brasileiros, houve um processo marcado por conflitos entre a corporação médica e os demais agentes que atuavam no interior do espaço asilar, no qual a primeira obteve a centralização da administração das instituições em suas mãos e a subordinação formal dos demais trabalhadores e das práticas que lhes eram correspondentes ao poder e ao saber médico (MACHADO, 1978; CUNHA, 1986; GUSSI, 1987).

Todavia, para que pudessem deter efetivamente o controle do espaço asilar e operar os procedimentos disciplinares que transformariam o hospício num espaço terapêutica, ao longo da primeira metade do século XX, os psiquiatras empreenderam um processo de disciplinamento dos agentes de enfermagem no qual estes incorporaram, às suas práticas e à sua visão de mundo, a concepção médica dominante sobre doença mental, doente mental e as formas de tratá-lo, no período compreendido entre as décadas de 20 e 50. Para assegurar a assimilação de tal concepção entre os agentes de enfermagem, sobretudo entre aqueles que possuíam um grau de escolaridade elementar, os psiquiatras tomaram a si a preparação da força de trabalho nelas empregada que, como foi visto, em sua maioria não buscava este tipo de trabalho por vocação ou altruísmo, mas por motivações de natureza econômica, determinadas pela situação em que se encontrava o mercado de trabalho brasileiro.

\section{HISTORICAL ANALYSIS OF NURSING PRACTICES IN THE FIELD OF PSYCHIATRIC CARE IN BRAZIL IN THE PERIOD COMPREHENDED BETWEEN THE 20S AND 50S}

This study focuses on the relation between the psychiatric project that had been established in Brazil from the end of the XIX century and the practices of the nursing staff preparation developed in Brazilian psychiatric institutions, between the 20 s and 5Os, using oral history as the research method. Through the historical reconstruction of certain aspects that characterized the psychiatric care organization in this country and the ways assumed by the processes of formation of the nursing staff in those institutions, it was verified that nursing constituted a fundamental element for the establishment of the asylum assistance model adopted in Brazil.

KEY WORDS: psychiatric nursing, oral history, teaching

\section{ANÁLISIS HISTPORICO DE LAS PRÁCTICAS DE ENFERMERÍA EN EL CAMPO DE LA ASISTENCIA PSIQUIÁTRICA EN EL BRASIL, EN EL PERIODO COMPRENDIDO ENTRE LAS DÉCADAS 1920 A 1950}

Este estudio enfoca la relación existente entre el proyecto psiquiátrico implementado en el Brasil a partir del final del siglo XIX y las prácticas de preparación de personal de enfermería que trabajan en instituciones psiquiátricas brasileñas, entre los años 20 y 50, utilizando la historia oral como método de investigación. A través de la conformación de ciertos aspectos que caracterizaron la organización de la asistencia psiquiátrica en el país y las formas asumidas por los procesos de formación de 
personal de enfermería en aquellos establecimientos, se verificó que la enfermería constituyó un elemento fundamental para la implementación del modelo asistencial en asilo, adoptado en el Brasil.

TÉRMINOS CLAVES: enfermería psiquiátrica, historia oral, enseñanza

\section{REFERÊNCIAS BIBLIOGRÁFICAS}

01. ALBERTI, V. História oral: a experiência do Cpdoc. Rio de Janeiro: Centro de Pesquisa e Documentação de História Contemporânea do Brasil, 1989. 197 p.

02. BIRMAN, J. A psiquiatria como discurso da moralidade. Rio de Janeiro: Graal, 1978, 453 p.

03. CERQUEIRA, L. Psiquiatria social - problemas brasileiros de saúde mental. Rio de Janeiro, São Paulo: Atheneu, 1989. 306p.

04. COSTA, J.F. História da Psiquiatria no Brasil. 4. ed. Rio de Janeiro: Xenon Ed., 1989. 187 p.

05. CUNHA, M.C.P. O espelho do mundo: Juquery, a história de um asilo. Rio de Janeiro: Paz e Terra, 1986. 217 p.

06. FERNANDES, J.D. O ensino de enfermagem e de enfermagem psiquiátrica no Brasil. Salvador, 1982. 111 p. Dissertação (Mestrado) - Câmara de Ensino de Pós-Graduação e Pesquisa, Universidade Federal da Bahia.

07. FOUCAULT, M. Vigiar e punir: a história da violência nas prisões. Petrópolis: Vozes, 1977. $277 \mathrm{p}$.

08. GODOY, J. A psiquiatria no Rio Grande do Sul. Rio de Janeiro: O Cruzeiro, 1952. 461 p.

09. GUSSI, M.A. A institucionalização da psiquiatria e do ensino de enfermagem psiquiámca no Brasil. Ribeirão Preto, 1987. 73 p. Dissertação (Mestrado) - Escola de Enfermagem de Ribeirão Preto, Universidade de São Paulo.

10. JACOBINA, R.R. O asilo e a constituição da psiquiatria na Bahia. Salvador, 1982. 107p. Dissertação (Mestrado) - Câmara de Ensino de Pós-Graduação e Pesquisa, Universidade Federal da Bahia.

11. MACHADO, R. et al. Danação da norma: medicina social e constituição da psiquiatria no Brasil. Rio de Janeiro: Graal, 1978. 559 p.

12. MELlO, G.N. de. Magistério de $\mathbf{1}^{\mathbf{0}}$ grau: da competência técnica ao compromisso político. 3 . ed. São Paulo: Cortez, 1982. 151 p.

13. MIRANDA, C.M.L. O parentesco imaginário hístória e representação social da loucura nas relações do espaço aguar. Rio de Janeiro, 1990. 227 p. Tese (Livre-Docência) - Escola de Enfermagem Alfredo Pinto, Universidade do Rio de Janeiro.
14. MOREIRA, A. Escola de Enfermagem Alfredo Pinto - 100 anos de história. Rio de Janeiro, 1990. Dissertação (Mestrado) - Escola de Enfermagem Alfredo Pinto, Universidade do Rio de Janeiro.

15. MOREIRA, J. Qualidades necessárias ao enfermeiro de psychopatas. Arq. Bras. de Higiene Mental, Rio de Janeiro, v.6, n. 2, p.8186, abr./jun. 1933.

16. OGATA, M.N. Contribuição à história da enfermagem psiquiátrica brasileira. Ribeirão Preto, 1992. 75 p. Dissertação (Mestrado) Escola de Enfermagem de Ribeirão Preto, Universidade de São Paulo.

17. PACHECO E SILVA, A.C. Cuidados aos psychopatas. 2. ed. Rio de Janeiro: Guanabara Waissman-Koogan, 207 p. s/d.

18. PORTO-CARRERO, J.P. Enfermagem no tratamento das neuroses. Arq. Bras. de Higiene Mental, Rio de Janeiro, v. 5, n. 1, p. 4-15, jan/ set. 1932.

19. RESENDE, H. Política de saúde mental no Brasil. ln: COSTA, N. R.; TUNDIS, S.A- (orgs.). Cidadania e loucura: políticas de saúde mental no Brasil. Petrópolis: Vozes/ABRASCO, 1987. $288 \mathrm{p}$.

20. RIBEIRO, M.A.R. (coord.). Trabalhadores urbanos e ensino profissional. 2.ed. Campinas: Editora da UNICAW, 1986. 308 p.

21. ROCHA, F.F. da. Hospício e colônias do Juquery: vinte anos de assistência aos alienados em São Paulo. São Paulo: Typ. Brasil Rotschild, 1912. $71 \mathrm{p}$.

22. ROXO, H. Idéias atuais sobre psiquiatria. Arq. Bras. de Higiene Mental, Rio de Janeiro, v. 15, n. I, p. 924, nov. 1944.

23. SAFFIOTI, H. A mulher na sociedade de classes: mito e realidade. Petrópolis: Vozes, 1976.

24. SILVA, G.B. da. Enfermagem profissional: análise crítica. São Paulo: Cortez, 1986. 143 p.

25. SOUZA, D. Notícia histórica sobre as origens da assistência a psicopatas no Rio Grande do Sul e sua avaliação. In: Polyanthéia Riograndense. Porto Alegre: Globo, 1942, p. 76-80. 


\section{ANEXO 1}

\section{ROTEIRO DE ENTREVISTA}

01. O que o (a) levou a trabalhar em psiquiatria (enfermagem psiquiátrica)?

02. Que tipo de formação o sr.(sra.) recebeu para trabalhar em psiquiatria?

03. Quem foram seus professores e que tipo de influência exerceram em sua formação?

04. Como era estruturado o serviço ou hospital no qual o sr.(sra.)trabalhou?

05. Como era o relacionamento dos profissionais de enfermagem entre si?

06. E com a equipe médica?

07. Como eram tratados os pacientes?

08. Que tipo de tratamentos eram empregados? Quais as condutas mais adotadas?

09. O que se pensava sobre atendimento de saúde no país?

10. Qual a visão que o sr. (sra) tinha sobre doença mental? 